\title{
The $\alpha$ integrin cytoplasmic motif KXGFFKR is essential for integrin-mediated leukocyte adhesion
}

\author{
MASAYOSHI OHKURO ${ }^{1}$ and IEHARU HISHINUMA ${ }^{2}$ \\ ${ }^{1}$ Tsukuba Research Laboratories, Eisai Co., Ltd., 5-1-3 Tokodai, Tsukuba, Ibaraki 300-2635, Japan; \\ ${ }^{2}$ Eisai Research Institute of Boston Inc., 4 Corporate Drive, Andover, MA 01810, USA
}

Received September 15, 2009; Accepted November 6, 2009

DOI: $10.3892 /$ ijmm_00000363

\begin{abstract}
During the development of autoimmune and inflammatory diseases, infiltration by multiple leukocyte types is commonly observed at the site of inflammation. These cells are chemotactically recruited via activated integrins expressed on their cell surfaces. However, the detailed mechanism of integrin activation has not been fully elucidated. A specific and highly conserved cytoplasmic amino acid sequence, lysine-X-glycine-phenylalanine-phenylalanine-lysine-arginine (KXGFFKR), is located in the immediate vicinity of the membrane-spanning domain of all $\alpha$ integrins. In this study, we investigated the role of the KXGFFKR motif in the adhesion of leukocytes to human umbilical-vein endothelial cells (HUVEC). Pre-treatment of human neutrophils with a membrane-permeable peptide-linked KVGFFKR decreased cell adhesion to HUVEC induced by a complement activation product, C5a and formyl-methionine-leucine-phenylalanine. Similar inhibitory efficacies of this peptide were observed in $\mathrm{T}$ cell adhesion. Our data therefore demonstrate that a highly conserved sequence in the $\alpha$ integrins, KXGFFKR, is pharmacologically essential for integrin activation during leukocyte adhesion by both neutrophils and T cells.
\end{abstract}

Correspondence to: Dr Masayoshi Ohkuro, Tsukuba Research Laboratories, Eisai Co., Ltd., 5-1-3 Tokodai, Tsukuba, Ibaraki 3002635, Japan

E-mail: m-okuro@hhc.eisai.co.jp

Abbreviations: Antp $_{43-58}$,Drosophila antennapedia homeoprotein; BSA, bovine serum albumin; KXGFFKR, lysine-x-glycinephenylalanine-phenylalanine-lysine-arginine; HUVEC, human umbilical vein endothelial cells; PMA, phorbol 12-myristate 13-acetate; fMLP, formyl-methionine-leucine-phenylalanine; BCECF-AM, 3'-O-acetyl-2',7'-bis (carboxyethyl)-4 or 5-carboxy fluorescein diacetoxymethyl ester; ICAM-1, intercellular adhesion molecule-1; VCAM-1, vascular cell adhesion molecule-1; TNF $\alpha$, tumor necrosis factor alpha

Key words: integrins, leukocyte adhesion, lysine-x-glycinephenylalanine-phenylalanine-lysine-arginine motif

\section{Introduction}

Integrins belong to a superfamily of cell adhesion receptors that primarily recognize extracellular matrix ligands and cellsurface ligands. Although originally identified as adhesion molecules, these molecules are now known to play key roles in embryonic development, immune response, leukocyte trafficking, and hemostasis, as well as in the pathogenesis of many diseases, including those associated with inflammation and autoimmune responses (1). Infiltration by multiple leukocyte types is commonly observed at the site of inflammation during the development of autoimmune and inflammatory diseases (2). Since anti-integrin antibody treatment and leukocytapheresis with a leukocyte-removal column have shown clinical benefits (3-6), several therapeutic strategies have been explored to prevent leukocyte recruitment by blocking individual chemoattractants, their receptors, or several integrins (7).

Integrins consist of transmembrane $\alpha \beta$ heterodimers. Nineteen $\alpha$ and eight $\beta$ subunits have been identified in mammals, generating 24 different $\alpha \beta$ combinations. Among these, $\alpha_{L} \beta_{2}, \alpha_{4} \beta_{1}, \alpha_{4} \beta_{7}, \alpha_{M} \beta_{2}, \alpha_{2} \beta_{1}$, and $\alpha_{5} \beta_{1}$ are expressed mainly in leukocytes (8). To achieve integrin-mediated leukocyte adhesion, integrins must be transiently activated through changes in affinity or avidity after cells are stimulated by a chemoattractant in a process referred to as inside-out signal and/or integrin activation (9-11). However, the detailed mechanism of integrin activation has not yet been clarified.

A specific and highly conserved cytoplasmic amino acid sequence, KXGFFKR, is located in the immediate vicinity of the membrane-spanning domain of all $\alpha$ integrins (12). Several proteins, including calreticulin and paxillin, have been reported as capable of binding to the KXGFFKR motif (12-16). Among these proteins, calreticulin, which was first identified as a calcium-dependent chaperone, has been recognized as a multifunctional protein (17). Calreticulin interacts with the conserved sequence of $\alpha$ integrins, and the introduction of antibodies or antisense oligonucleotides against calreticulin into Jurkat cells inhibits $\alpha_{2} \beta_{1}$-mediated cell adhesion to type I collagen $(18,19)$. In addition to the affinity of the KXGFFKR motif for these proteins, a deletion or point mutation of the membrane-proximal region that includes the KXGFFKR motif results in constitutively activated integrin, suggesting that the motif's affinity for $\beta$ integrins keeps the integrin in a 
resting state (20-23). These reports suggest that the KXGFFKR motif of the $\alpha$ integrins plays a pivotal role in integrin activation and the regulation of leukocyte adhesion.

In this study, we first examined the importance of integrin activation induced by several stimuli in the adhesion of neutrophils and $\mathrm{T}$ cells to human umbilical-vein endothelial cells (HUVEC). Pretreatment of HUVEC with tumor necrosis factor $\alpha(\mathrm{TNF} \alpha)$, in which adhesion molecules, such as intercellular adhesion molecule-1 (ICAM-1) and vascular cell adhesion molecule-1 (VCAM-1), are strongly expressed, did not clearly affect the adhesion ratio of leukocytes to resting or activated HUVEC. We further investigated the role of the KXGFFKR motif in integrin-mediated cell adhesion by using a cell membrane-permeable peptide. This 16 -amino acid peptide was unexpectedly found during research on the DNAbinding region of the Drosophila antennapedia homeoprotein $\left(\mathrm{Antp}_{43-58}\right)$ (24). Since Antp $\mathrm{A}_{4-58}$ is highly efficiently captured by various types of cells in a temperature-independent manner, it has been used to convey peptides and oligonucleotides into cells $(24,25)$. Here, we constructed the 23 -amino acid peptide of Antp ${ }_{43-58}$-linked KVGFFKR to transfer KVGFFKR inside leukocytes. Pretreatment of neutrophils with Antp $_{43-58}$-linked KVGFFKR decreased the induction of cell adhesion to HUVEC by a complement activation product, C5a and formylmethionine-leucine-phenylalanine (fMLP). Similar inhibitory efficacies of Antp $43-58$-linked KVGFFKR peptide were observed in the adhesion of $\mathrm{T}$ cells stimulated by phorbol 12-myristate 13-acetate (PMA) and anti-CD3 antibody. These data suggest that a highly conserved sequence in the cytoplasmic domain of the $\alpha$ integrins, KXGFFKR, plays one or more crucial roles in the regulation of integrin activation during leukocyte adhesion of both neutrophils and T cells.

\section{Materials and methods}

Cell culture. We purchased HUVEC and fetal bovine serum (FBS, Sanko Junyaku, Tokyo, Japan) and cultured cells in MCDB-131 (Chlorella Industries) that contained ECGS (Becton Dickinson), antibiotic and antimicotic solution (Gibco BRL) and 10\% FBS in a type I collagen-immobilized 96-well plate (Asahi Techno Glass) in a $\mathrm{CO}_{2}$ incubator (Hirasawa Co., Ltd). The resultant cell suspension was added to a 96 -well plate $\left(1.2 \times 10^{4}\right.$ cells/well $)$, immobilized with type I collagen, and cultured for 3 days at $37^{\circ} \mathrm{C}$. HUVEC were stimulated with $1 \mathrm{ng} / \mathrm{ml}$ TNF $\alpha$. After $4 \mathrm{~h}$, HUVEC were then fixed with phosphate-buffered saline containing $0.025 \%$ glutaraldehyde (Kanto Chemical Co., Ltd.) and the plates were stored at $4^{\circ} \mathrm{C}$ until use.

Quantification of adhesion molecule expression on HUVEC. The quantification of adhesion molecule expression was determined by the enzyme-linked immunosorbent assay as previously reported (26).

Isolation of human neutrophils and T cells. Human neutrophils and T cells were isolated from the peripheral blood of healthy volunteers by means of sedimentation using dextran (Nacalai Tesque) and Ficoll-Paque PLUS (GE Healthcare). Mononuclear cells were collected from the interface between the plasma and the Ficoll layer, and $\mathrm{T}$ cells were purified using a nylon fiber column (Wako Junyaku). Neutrophils were obtained after hypotonic lysis of the contaminating erythrocytes, as previously reported (27).

Labeling of cells. Cells were labeled with 3'-O-acetyl-2',7'-bis (carboxyethyl)-4 or 5-carboxy fluorescein, diacetoxymethyl ester (BCECF-AM, Wako), as previously reported (10). After $45 \mathrm{~min}$ at $37^{\circ} \mathrm{C}$ in the dark, cells were washed and then suspended with RPMI-1640 (Sigma-Aldrich) containing $1 \mathrm{mg} / \mathrm{ml} \mathrm{BSA}$, and then stored at $4^{\circ} \mathrm{C}$ until use.

Cell adhesion assay. To each well containing a HUVEC monolayer, pretreated or not with $\mathrm{TNF} \alpha$, we added BCECFAM-labeled T cells $\left(2.5 \times 10^{5}\right)$ stimulated with $10 \mathrm{nM}$ PMA (Sigma-Aldrich), $10 \mu \mathrm{g} / \mathrm{ml}$ anti-CD3 antibody (UCTH-1, Immunotech) or mouse IgG1 (anti-TNP, PharMingen). To stimulate neutrophil adhesion, we used $100 \mathrm{nM} \mathrm{C5a}$ and $100 \mathrm{nM}$ fMLP. After $45 \mathrm{~min}$ at $37^{\circ} \mathrm{C}$, we removed non-adhering cells by washing with RPMI-1640, and then estimated the number of adhering cells from the fluorescence intensity measured at an excitation wavelength of $485 \mathrm{~nm}$ and an emission wavelength of $535 \mathrm{~nm}$ on a chemiluminometer (ARVO ${ }^{\text {TM }}$ SX 1420 multi-label counter, Tokyo, Japan). We measured the time-dependency of adhesion by incubating the HUVEC at $37^{\circ} \mathrm{C}$ for $0,5,15$, and $30 \mathrm{~min}$ in the neutrophil treatment and for $0,15,30,60$, and $90 \mathrm{~min}$ in the $\mathrm{T}$ cell treatment. We measured the fluorescence intensity before and after washing, and expressed the adhesion ratio as the post-washing fluorescence value divided by the pre-washing fluorescence value.

Peptide synthesis and pretreatment of leukocytes with Antp ${ }_{43-58^{-}}$ linked peptide. Antp ${ }_{43-58}$-linked KVGFFKR peptide (RQIKI WFQNRRMKWKK-KVGFFKR) was synthesized by Sawady Technology (Tokyo, Japan). BCECF-AM-labeled neutrophils or $\mathrm{T}$ cells $\left(2 \times 10^{7}\right.$ cells $\left./ \mathrm{ml}\right)$ were incubated for $2 \mathrm{~h}$ at $4^{\circ} \mathrm{C}$ at concentrations ranging from 0 to $200 \mu \mathrm{g} / \mathrm{ml}$ of Antp $_{43-58}$-linked KVGFFKR peptide.

Statistical analysis. Data are expressed as the means \pm SEM. All statistical analyses were performed using the SAS software package (SAS Institute). We used an unpaired t-test for comparisons between two groups.

\section{Results}

Leukocyte adhesion to HUVEC depends upon integrin activation induced by stimuli. To achieve integrin-mediated adhesion of leukocytes, integrin must be activated by one or more stimuli (8-11). We firstly examined the adhesion characteristics of resting and activated leukocytes to resting or TNF $\alpha$-activated HUVEC. The expression of adhesion molecules such as ICAM-1 and VCAM-1 were significantly upregulated on TNF $\alpha$-activated HUVEC ( $>00.005$, data not shown). As indicated in Fig. 1A, the integrin stimulators fMLP and C5a both significantly increased adhesion of neutrophils to both resting and $\mathrm{TNF} \alpha$-activated HUVEC. In contrast, neutrophils that were not activated using these stimuli showed a much lower cell adhesion ratio, and there was no clear difference in the adhesion ratio between resting and $\mathrm{TNF} \alpha-$ 
A

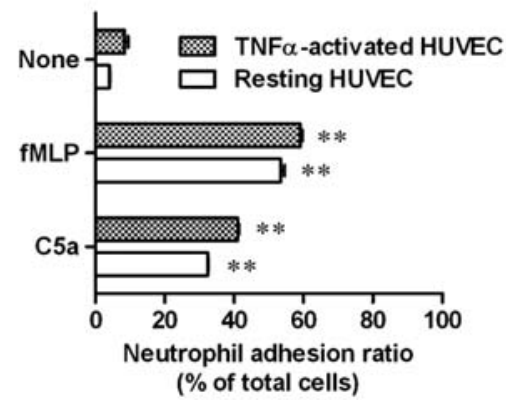

B

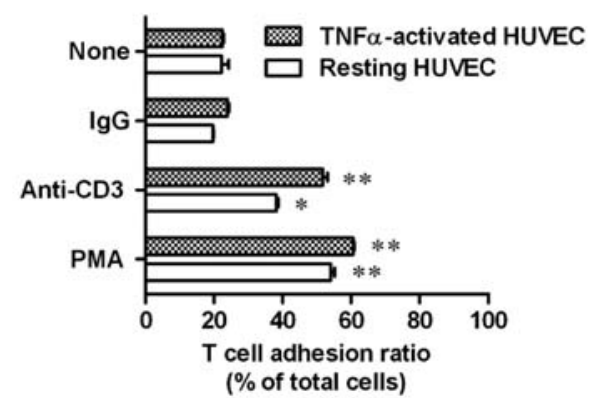

Figure 1. Adhesion of leukocytes to HUVEC depended upon activation of integrin in the leukocytes. HUVEC monolayers in 96-well plates were incubated for $4 \mathrm{~h}$ in the presence or absence of $1 \mathrm{ng} / \mathrm{ml} \mathrm{TNF} \alpha$. To each well containing a HUVEC monolayer, we added BCECF-AM-labeled (A) neutrophils or (B) T cells with each stimulus (in A, none, fMLP, or C5a; in B, none, IgG, anti-CD3 antibody, or PMA). After 45 min at $37^{\circ} \mathrm{C}$, non-adhering cells were washed away and the number of cells adhering to the HUVEC was estimated by measuring the fluorescence intensity of BCECF-AM. Each bar represents the means \pm SEM $(\mathrm{n}=3) .{ }^{*} \mathrm{P}<0.05$ and ${ }^{* *} \mathrm{P}<0.001$ versus the none-stimulated control in each status of HUVEC.

A

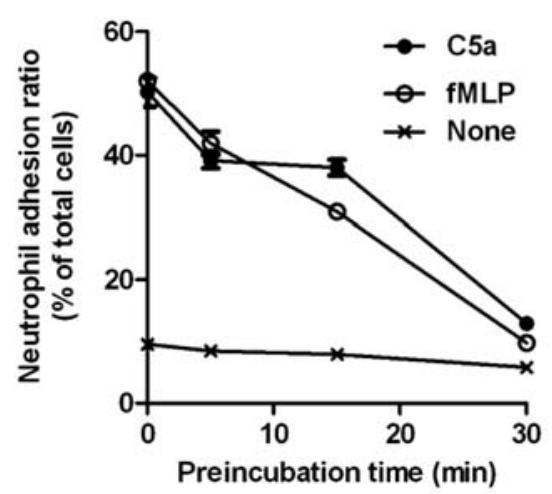

B

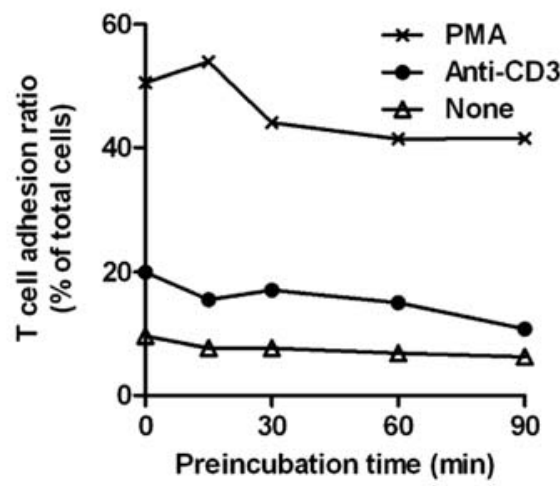

Figure 2. Adhesion of leukocytes to HUVEC is an early and transient event. We preincubated BCECF-AM-labeled (A) neutrophils or (B) T cells with each stimulus (in A, none, fMLP, or C5a; in B, none, anti-CD3 antibody, or PMA) for various durations at $37^{\circ} \mathrm{C}$, and then added them to a 96 -well plate containing a HUVEC monolayer that had been pretreated with $1 \mathrm{ng} / \mathrm{ml}$ of TNF $\alpha$. After $45 \mathrm{~min}$, non-adhering cells were washed away and the number of adhering cells was determined by measuring the fluorescence intensity of BCECF-AM. Each value represents the means \pm SEM ( $\mathrm{n}=3$ ).

activated HUVEC. Similar results were obtained for adhesion of T cells induced by the PMA and anti-CD3 antibody stimuli (Fig. 1B). Because the adhesion of neutrophils to HUVEC is mediated by $\alpha_{M} \beta_{2} / \alpha_{L} \beta_{2}$ integrins (11), and the adhesion of T cells to HUVEC is mainly mediated by $\alpha_{L} \beta_{2} / \alpha_{4} \beta_{1}$ integrins (28), these findings suggest that the adhesiveness of both neutrophils and $\mathrm{T}$ cells depends mainly upon activation of leukocyte integrins induced by various stimuli, regardless of whether HUVEC were activated or resting.

Leukocyte adhesion to HUVEC is an early and transient event. Next, we examined additional characteristics of leukocyte adhesion to HUVEC in a time-dependent manner. Neutrophils or $\mathrm{T}$ cells were pretreated using each stimulus for durations of up to $30 \mathrm{~min}$ (neutrophil treatment) and $90 \mathrm{~min}$ (T cells) at $37^{\circ} \mathrm{C}$, then added them to the 96-well plates that contained TNF $\alpha$-activated HUVEC. The maximum cell adhesion ratio for neutrophils was observed at a preincubation time of $0 \mathrm{~min}$, and the cell adhesion ratio gradually decreased to the basal level by $30 \mathrm{~min}$ (Fig. 2A). T cell adhesion induced by antiCD3 antibody showed an early but transient decrease (Fig. 2B), whereas T cell adhesion induced by PMA increased transiently, but then declined and reached a stable level near $44 \%$ after $30 \mathrm{~min}$; this level was sustained for at least $90 \mathrm{~min}$ of preincubation time (Fig. 2B). Integrin activation of $\mathrm{T}$ cells induced by PMA seemed to be higher than that induced by anti-CD3 antibody, and was sustained longer.

Cytochalasin B enhances leukocyte adhesion to HUVEC. Integrins on leukocytes are inactive in the absence of stimuli. The mechanism by which PMA enhanced leukocyte adhesion may be that PMA increases the mobility of integrin in the leukocyte plasma membrane (29). In addition, (L integrinmediated lymphocyte adhesion was induced by cytochalasins, which disrupts the organization of actin filaments $(29,30)$. Accordingly, the attachment of integrin to the actin cytoskeleton may maintain the integrin in an inactive state in resting lymphocytes. Cytochalasin B dramatically enhanced the induction by both C5a and fMLP of neutrophil adhesion to TNF $\alpha$-activated HUVEC. However, no upregulation of neutrophil adhesion to resting HUVEC was observed after pretreatment of cells with cytochalasin B (Fig. 3A). Cytochalasin B 
A

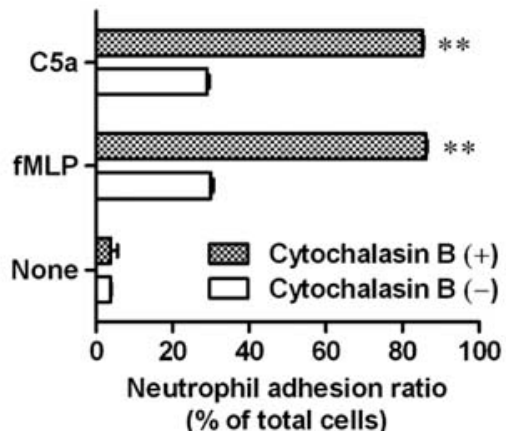

B

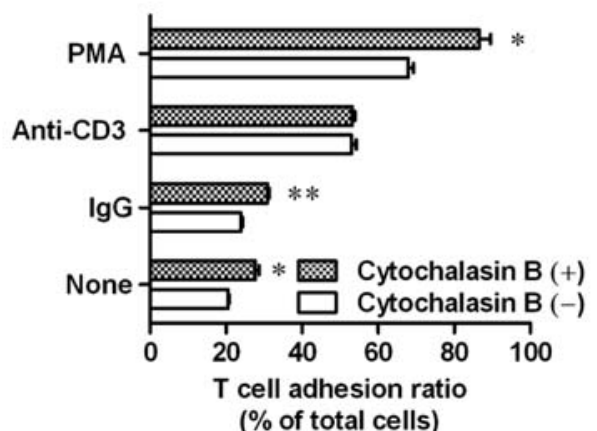

Figure 3. Cytochalasin B increases leukocyte adhesion to HUVEC. BCECF-AM-labeled (A) neutrophils or (B) T cells pretreated with $5 \mu \mathrm{g} / \mathrm{ml}$ cytochalasin B and each stimulus (in A, none, fMLP, or C5a; in B, none, IgG, anti-CD3 antibody, or PMA) for 5 min at $37^{\circ} \mathrm{C}$, and were then added to a 96 -well plate containing a HUVEC monolayer that had been pretreated with $1 \mathrm{ng} / \mathrm{ml}$ of TNF $\alpha$. After $45 \mathrm{~min}$, non-adhering cells were washed away and the number of adhering cells was determined by measuring the fluorescence intensity of BCECF-AM. Each bar represents the means $\pm \mathrm{SEM}$ ( $\mathrm{n}=3$ ). ${ }^{*} \mathrm{P}<0.01$ and ${ }^{* *} \mathrm{P}<0.001$ versus the cytochalasin-untreated control in each stimulus.

A

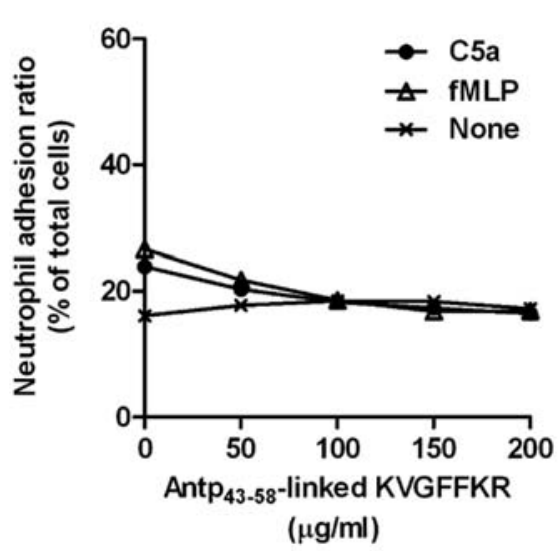

B

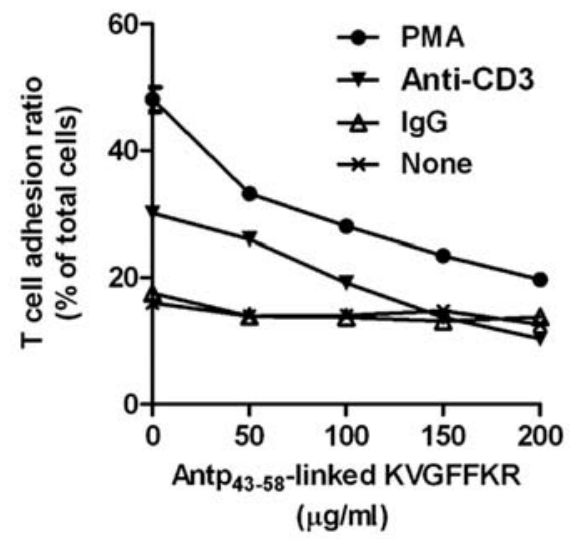

Figure 4. Antp $43-58$-linked KVGFFKR peptide inhibits stimuli-induced leukocyte adhesion to HUVEC. BCECF-AM-labeled (A) neutrophils or (B) T cells were pretreated with various concentrations of a membrane-permeable peptide (Antp $43-58^{-}$-linked KVGFFKR) for $2 \mathrm{~h}$ at $4^{\circ} \mathrm{C}$. To each well containing TNF $\alpha$-activated HUVEC, we added neutrophils or T cells pretreated with Antp $43-58$-linked KVGFFKR along with each stimulus (in A, none, fMLP, or C5a; in B, none, IgG, anti-CD3 antibody, or PMA). After 45 min at $37^{\circ} \mathrm{C}$, non-adhering cells were washed away and the number of adhering cells was determined by measuring the fluorescence intensity of BCECF-AM. Each value represents the means \pm SEM ( $n=3)$.

also enhanced the adhesion of $\mathrm{T}$ cells to resting and PMAstimulated HUVEC, but did not affect adhesion after stimulation by anti-CD3 (Fig. 3B).

The Antp ${ }_{43-58}$-linked KVGFFKR peptide inhibits stimulusinduced leukocyte adhesion to HUVEC. To learn the role of the conserved KXGFFKR sequence of the $\alpha$ integrin cytoplasmic domain in leukocyte adhesion, we used the Antp ${ }_{43-58}$ membranepermeable peptide (RQIKIWFQNRRMKWKK) to convey KVGFFKR into HUVEC. Since this internalization is not temperature-dependent $(24,25)$, BCECF-AM-labeled leukocytes were pretreated with Antp 43-58 -linked KVGFFKR (RQI KIWFQNRRMKWKK-KVGFFKR) for $2 \mathrm{~h}$ at $4^{\circ} \mathrm{C}$. As shown in Fig. 4A, Antp 43-58 -linked KVGFFKR peptide inhibited the adhesion of neutrophils to TNF $\alpha$-activated HUVEC induced by both C5a and fMLP in a dose-dependent manner. However, in the absence of the integrin activators C5a and fMLP, the adhesion of neutrophils was not affected by this peptide (Fig. 4A). T cells exhibited a similar inhibitory effect

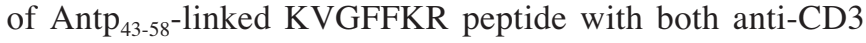
antibody and PMA (Fig. 4B). However, Antp ${ }_{43-58}$-linked KVGFFKR peptide did not inhibit PMA and TNF $\alpha$ induced the expression of ICAM-1 on the surface of HUVEC (data not shown), indicating that the Antp $43-58$-linked KVGFFKR peptide exhibited specific inhibition of stimuli-induced adhesion by both neutrophils and T cells.

\section{Discussion}

Our study demonstrated the connection between a highly conserved sequence in the $\alpha$ integrins (the KXGFFKR motif) and leukocyte adhesion. We showed that adhesion of both neutrophils and $\mathrm{T}$ cells was dramatically regulated by the state of activation of the leukocytes in the presence of typical stimuli, regardless of whether HUVEC were activated or resting or whether expression of cell-surface adhesion molecules such as ICAM-1 increased (Fig. 1). A similar response of CD4 ${ }^{+}$ $\mathrm{T}$ cell adhesion to HUVEC was previously reported (28). If 
the recruitment of leukocytes is chosen as a therapeutic target, the integrins of the leukocytes therefore appear to be a more attractive and efficacious drug target than adhesion molecules expressed in cells. In fact, anti- $\alpha_{\mathrm{L}}$ integrin antibody (Raptiva ${ }^{\circledR}$ ) and the anti- $\alpha_{4}$ integrin antibody (Tysabri ${ }^{\circledR}$ ) have been developed and launched, and have shown remarkable efficacies in ameliorating psoriasis and multiple sclerosis in patients, respectively $(3,5)$.

The adhesion of both neutrophils to HUVEC and of T cells to immobilized ICAM-1 was transiently upregulated by the stimuli C5a and anti-CD3 antibody, respectively $(10,11)$. Here, we evaluated the adhesion of both neutrophils and $\mathrm{T}$ cells to TNF $\alpha$-activated HUVEC in the presence of various kinds of stimuli. PMA-induced T cell adhesion to HUVEC was not transient, and instead remained elevated (Fig. 2B). However, the enhancement of leukocyte adhesion by other physiological stimuli were transient (Fig. 2). These transient events are physiologically reasonable because they allow leukocytes to migrate efficiently from blood vessels into the surrounding inflamed tissues.

To further understand the correlation between integrinmediated leukocyte adhesion and the actin cytoskeleton network, we examined the effect of cytochalasin B, which can disrupt the actin cytoskeleton network (Fig. 3). We found evidence that both resting and PMA-stimulated T cells pretreated with cytochalasin B exhibited increased cell adhesion. As has been reported in previous lymphocyte studies $(20,29)$, the association of $\alpha_{\mathrm{L}}$ integrin with the actin cytoskeleton keeps $\alpha_{\mathrm{L}}$ integrin in an inactive state, and dislodging the actin cytoskeleton with cytochalasins decreases its restriction of this integrin, thereby enhancing the adhesion of $\mathrm{T}$ cells mediated by $\alpha_{\mathrm{L}}$ integrin. In addition, cytochalasin B enhanced neutrophil adhesion in the presence of C5a and fMLP, but no upregulation of adhesion was caused by cytochalasin $\mathrm{B}$ in the resting neutrophils (Fig. 3A). In previous research, cytochalasin B enhanced several fMLP-stimulated responses of neutrophils, including aggregation, superoxide production, and degradation by increasing the response of diacylglycerol to fMLP (31). Thus, dramatic enhancement of neutrophil adhesion induced by fMLP and C5a along with the treatment of neutrophils with cytochalasin B might result from a priming effect, such as diacylglycerol enhancement, rather than from disruption of the actin cytoskeleton network.

An additional finding of our study is that the membranepermeable Antp 43-58 -linked KVGFFKR peptide inhibited the stimuli-induced adhesion of both neutrophils and $\mathrm{T}$ cells to HUVEC (Fig. 4). Notably, this peptide did not show any inhibitory effect in adhesion to resting leukocytes, suggesting that the KXGFFKR motif may be related not to basal adhesion of resting leukocytes but rather to the activated integrin state induced by various stimuli.

One significant question raised by the results of our study relates to the mechanism by which the Antp 43-58 $_{\text {-linked }}$ KVGFFKR peptide inhibited leukocyte adhesion. A previous mutagenesis study indicated that a salt bridge between $\alpha_{\mathrm{IIb}}$ integrin that included KVGFFKR and $\beta_{3}$ integrin stabilized the interaction of the membrane's proximal region and maintained the integrins in a resting state (21). Deletion or point mutation of the membrane-proximal region that includes the KXGFFKR motif resulted in constitutively activated integrin (20-23), and integrin activation involves the spatial separation of the cytoplasmic tails of the two membraneproximal $\alpha$ and $\beta$ integrins (32). We propose two hypotheses that could explain this. First, the Antp $43-58$-linked KVGFFKR peptide competes with the native $\alpha$ integrin for association with the native $\beta$ integrin via a salt bridge. Second, it competes with a protein that binds to the KXGFFKR motif. Our results demonstrated that the Antp $_{43-58}$-linked KVGFFKR peptide did not enhance the adhesion of either neutrophils or T cells, suggesting that the Antp 43-58 -linked KVGFFKR peptide neither competes with the native $\alpha$ integrin for binding to the native $B$ integrin nor induces the spatial separation of the cytoplasmic tails of the two membrane-proximal $\alpha$ and $\beta$ integrins. Accordingly, the Antp $_{43-58}$-linked KVGFFKR peptide may compete with a native binding protein for the KVGFFKR motif, resulting in downregulation of integrin-mediated leukocyte adhesion. The most promising candidate for the binding protein appears to be calreticulin $(13,18,19)$. This is because calreticulin can interact with a broad range of $\alpha$ integrins via the KXGFFKR motif (13), and because the introduction of antibodies or antisense oligonucleotides against calreticulin into Jurkat cells inhibits $\alpha_{2} \beta_{1}$-mediated cell adhesion to type I collagen by preventing intracellular interactions between calreticulin and $\alpha$ integrins $(18,19)$. The mechanism by which the Antp 43-58 -linked KVGFFKR peptide can suppress the adhesion of both neutrophils and $\mathrm{T}$ cells mediated by several integrins may be due to disruption of the calreticulin- $\alpha$ integrin interaction.

In conclusion, our data demonstrated that a specific and highly conserved sequence, the KXGFFKR motif of $\alpha$ integrins, is pharmacologically essential for the activation of integrins in the regulation of leukocyte adhesion, and also highlights the KXGFFKR motif as a potential therapeutic target for inflammatory diseases. It has recently been accepted that association of the cytoskeleton talin protein with $B$ integrins is the final common step in integrin activation $(33,34)$. Further investigations are needed to clarify the mechanism or mechanisms by which these proteins regulate integrin activation in integrin-mediated cell functions.

\section{Acknowledgements}

We thank Dr Bruce Littlefield (Harvard Medical School, Osher Research Center) for his encouragement, and Akiyoshi Fukamizu (Center for Tsukuba Advanced Research Alliance and Graduate School of Life and Environmental Sciences, University of Tsukuba) for helpful advice and suggestions on this study.

\section{References}

1. Hynes RO: Integrins, Bidirectional allosteric signaling machines. Cell 110: 673-687, 2002.

2. Luster AD, Alon R and Von Andrian UH: Immune cell migration in inflammation: present and future therapeutic targets. Nature Immunol 6: 1182-1190, 2005.

3. Dubertret L, Sterry W, Bos JD, Chimenti S, Shumack S, Larsen CG, Shear NH and Papp KA: CLinical experience acquired with the efalizumab (Raptiva ${ }^{\circledR}$ ) (CLEAR) trial in patients with moderate-to-severe plaque psoriasis: results from a phase III international randomized, placebo-controlled trial. Br J Dermatol 155: 170-181, 2006. 
4. Sandborn WJ, Colombel JF, Enns R, Feagen BG, Hanauer SB, Lawrance IC, Panaccione R, Sanders M, Schreiber S, Targan S, Van Deventer S, Goldblum R, Despain D, Hogge GS and Rutgeerts P: Natalizumab induction and maintenance therapy for Crohn's disease. N Engl J Med 353: 1912-1925, 2005.

5. Polman CH, O'Connor PW, Havrdova E, Hutchinson M, Kappos L, Miller DH, Phillips T, Lublin FD, Giovannoni G, Wajgt A, Toal M, Lynn F, Panzara MA and Sandrock AW: A randomized, placebo-controlled trial of Natalizumab for relapsing multiple sclerosis. N Engl J Med 354: 899-910, 2006.

6. Izumi Y, Tominaga M, Iwanaga N, Huang M, Tanaka F, Aratake K, Arima K, Tamai M, Kamachi M, Nakamura H, Ida H, Origuchi T, Kawakami A and Eguchi K: Twenty-four-week follow-up examination of a leukocytapheresis therapy in rheumatoid arthritis. Mod Rheumatol 16: 20-23, 2006.

7. Kaneider NC, Leger AJ and Kuliopulos A: Therapeutic targeting of molecules involved in leukocyte-endothelial cell interactions. FEBS J 273: 4416-4424, 2006.

8. Springer TA: Traffic signals for lymphocyte recirculation and leukocyte emigration: The multistep paradigm. Cell 76: 301-314, 1994

9. Ley K, Laudanna C, Cybulsky MI and Nourshargh S: Getting to the site of inflammation: The leukocyte adhesion cascade updated. Nature Rev Immunol 7: 678-689, 2007.

10. Dustin ML and Springer TA: T-cell receptor cross-linking transiently stimulates adhesiveness through LFA-1. Nature 341: 619-624, 1989

11. Lo SK, Detmers PA, Levin SM and Wright SD: Transient adhesion of neutrophils to endothelium. J Exp Med 169: 1779-1793, 1989.

12. Williams MJ, Hughes PE, O'Toole TE and Ginsberg MH: The inner world of cell adhesion: Integrin cytoplasmic domains. Trends Cell Biol 4: 109-112, 1994.

13. Rojiani MV, Finlay BB, Gray V and Dedhar S: In vitro interaction of a polypeptide homologous human Ro/SS-A antigen (calreticulin) with highly conserved amino acid sequence in the cytoplasmic domain of integrin $\alpha$ subunits. Biochemistry 30: 9859-9866, 1991.

14. Löster K, Vossmeyer D, Hofmann W, Reutter W and Danker K: $\alpha 1$ integrin cytoplasmic domain is involved in focal adhesion formation via association with intracellular proteins. Biochem J 356: 233-240, 2001.

15. Daxecker H, Raab M, Bernard E, Devocelle M, Treumann A and Moran N: A peptide affinity column for the identification of integrin $\alpha_{\mathrm{II}}$-binding proteins. Anal Biochem 374: 203-212, 2008 .

16. Knoblauch A, Will C, Goncharenko G, Ludwig S and Wixler V: The binding of Mss4 to $\alpha$-integrin subunits regulates matrix metalloproteinase activation and fibronection remodeling. FASEB J 21: 497-510, 2007.

17. Michalak M, Corbett EF, Mesaeli N, Nakamura K and Opas M: Calreticulin, one protein, one gene, many functions. Biochem J 344: 281-292, 1999.

18. Leung-Hagesteijn CY, Milankov K, Michalak M, Wilkins J and Dedhar S: Cell attachment to extracellular matrix substrates is inhibited upon downregulation of expression of calreticulin, an intracellular integrin $\alpha$-subunit-binding protein. J Cell Sci 107: 589-600, 1994.

19. Coppolino M, Leung-Hagesteijn C, Dedhar S and Wilkins J: Inducible interaction of integrin $\alpha 2 \beta 1$ with calreticulin. J Biol Chem 270: 23132-23138, 1995.
20. Van Kooyk Y, Van Vliet SJ and Figdor CG: The actin cytoskeleton regulates LFA-1 ligand binding through avidity rather than affinity changes. J Biol Chem 274: 26869-26877, 1999.

21. Hughes PE, Diaz-Gonzalez F, Leong L, Wu C, McDonald JA, Shattil SJ and Ginsberg MH: Breaking the integrin hinge. A defined structural constraint regulates integrin signaling. J Biol Chem 271: 6571-6574, 1996.

22. Lu C and Springer TA: The $\alpha$ subunit cytoplasmic domain regulates the assembly and adhesiveness of integrin lymphocyte function-associated antigen-1. J Immunol 159: 268-278, 1997.

23. O'Toole TE, Katagiri Y, Faull RJ, Peter K, Tamura R, Quaranta V, Loftus JC, Shattil SJ and Ginsberg MH: Integrin cytoplasmic domains mediate inside-out signal transduction. J Cell Biol 124: 1047-1057, 1994

24. Derossi D, Joliot AH, Chassaing G and Prochiant A: The third helix of the Antennapedia homeodomain translocates through biological membranes. J Biol Chem 269: 10444-10450, 1994.

25. Derossi D, Calvet S, Trembleau A and Brunissen A: Cell internalization of the third helix of the Antennapedia homeodomain is receptor-independent. J Biol Chem 271: 1818818193, 1996.

26. Kaneko T, Clark RS, Ohi N, Kawahara T, Akamatsu H, Ozaki F, Kamada A, Okano K, Yokohama H, Muramoto K, Ohkuro M, Takenaka $\mathrm{O}$ and Kobayashi S: Inhibitors of adhesion molecules expression; The synthesis and pharmacological properties of 10H-Pyrazino[2,3-b][1,4]benzothiazine derivatives. Chem Pharm Bull 50: 922-929, 2002.

27. Fällman M, Gullberg M, Hellberg C and Anderson T: Complement receptor-mediated phagocytosis is associated with accumulation of phosphatidylcholine-derived diglyceride in human neutrophils. J Biol Chem 267: 2656-2663, 1992.

28. Shimizu Y, Newman W, Gopal TV, Horgan KJ, Graber N, Beall LD, Van Seventer GA and Shaw S: Four molecular pathways of T cell adhesion to endothelial cells: Roles of LFA-1, VCAM-1, and ELAM-1 and changes in pathway hierarchy under different activation conditions. J Cell Biol 113: 1203$1212,1991$.

29. Kucik DF, Dustin ML, Miller JM and Brown EJ: Adhesionactivating phorbol ester increases the mobility of leukocyte integrin LFA-1 in cultured lymphocytes. J Clin Invest 97: 2139-2144, 1996.

30. Yahara I, Harada F, Sekita S, Yoshihira K and Natori S: Correlation between effects of 24 different cytochalasins on cellular structures and cellular events and those on action in vitro. J Cell Biol 92: 69-78, 1982.

31. Honeycutt PJ and Niedel JE: Cytochalasin B enhancement of the diacylglycerol response in formyl peptide-stimulated neutrophils. J Biol Chem 261: 15900-15905, 1986.

32. Kim M, Carman CV and Springer TA: Bidirectional transmembrane signaling by cytoplasmic domain separation in integrins. Science 301: 1720-1725, 2003.

33. Tadokoro S, Shattil SJ, Eto K, Tai V, Liddington RC, de Pereda JM, Ginsberg MH and Calderwood DA: Talin binding to integrin $B$ tails. A final common step in integrin activation. Science 302: 103-106, 2003.

34. Wegener KL, Partridge AW, Han J, Pickford AR, Liddington RC, Ginsberg MH and Campbell ID: Structural basis of integrin activation by talin. Cell 128: 171-182, 2007. 